\title{
COEFICIENTES DE REPETIBILIDADE GENÉTICA DE CARACTERES EM PUPUNHEIRA ${ }^{1}$
}

\author{
JOÃO TOMÉ DE FARIAS NETO², GILBERTO YOKOMIZO ${ }^{3}$, ARNALDO BIANCHETTI ${ }^{3}$
}

\begin{abstract}
RESUMO - No Brasil, a pupunheira é uma planta muito útil na alimentação, seja como fonte de frutos seja para palmito. O interesse pela pupunheira como produtora de palmito deve-se a características de precocidade de produção, rusticidade, perfilhamento, palatabilidade. Estimativas de parâmetros genéticos, como a repetibilidade em pupunheira, são importantes por constituir ferramentas fundamentais no direcionamento de um programa de melhoramento genético. O objetivo do trabalho foi estimar os coeficientes de repetibilidade dos caracteres altura da planta, diâmetro da planta à altura do colo e peso de palmito em três avaliações, em pupunheira, por meio dos seguintes procedimentos estatísticos: análise de variância, componentes principais e análise estrutural. Foram também determinados os números de repetições necessárias para proporcionar níveis de certeza da predição do valor real do indivíduo. Os coeficientes de repetibilidade dos caracteres diâmetro à altura do colo e peso de palmito líquido são de baixa magnitude (inferiores a 0,4), indicando irregularidade de comportamento de uma avaliação para outra. Para o caráter altura da planta, três avaliações são necessárias para ter-se predições com confiabilidade de $80 \%$.Para o mesmo percentual de confiabilidade, são necessárias seis avaliações para os caracteres diâmetro à altura do colo e peso de palmito líquido.
\end{abstract}

Termos para indexação: melhoramento, seleção, Bactris gasipaes, palmito, características de crescimento.

\section{GENETIC REPEATABILITY COEFICIENT OF CARACTERS IN PEACH PALM}

ABSTRACT - In Brazil, the Bactris gasipaes palm is a very useful plant for food as a source of fruits or heart palm. The interest for this species is due to the precocity of the heart palm production, rusticity, straightening up, and palatability of the heart palm. Estimates of genetic parameters, such as repeatability, are very important and fundamental for breeding program. The objective of this research was to estimate the repeatability coefficients of the characters: plant height, plant diameter and heart palm weight, using variance analysis, principal components and structural analysis. It was also determined the minimum numbers of repetitions in order to determine critic levels of real prediction values of the individual. The repeatability coefficients of the stem base diameter, plant height and heart palm weight were of low magnitude (lower than 0.4), indicating irregular behavior from one evaluation to another. For plant height, three measures are necessary to have predictions with $80 \%$ confidence. For the same confidence, for stem base diameter and heart-of-palm weight six measures will be necessary.

Index terms: breeding, correlation, Bactris gasipaes, heart palm, growing characteristics.

\section{INTRODUÇÃO}

O Brasil é o maior produtor, exportador e consumidor de palmito do mundo, atingindo um consumo de 100 mil toneladas/ano, que se baseia principalmente na extração de palmáceas nativas de espécies do gênero Euterpe, como a juçara (E. edulis) e o açaí (E. oleracea), apesar de poder ser extraído de grande número de gêneros e espécies de palmeiras. Nos últimos anos, o cultivo da pupunheira (Bactris gasipaes Kunth), visando à produção de palmito, tem sido crescente no Brasil. O interesse pela pupunheira, além de ser uma cultura perene, deve-se a: precocidade, rusticidade, perfilhamento, palatabilidade e nãoescurecimento do palmito após o corte (Bovi, 1994; Tonef et al., 1999).

Nos estudos com progênies ou cultivares, compreendendo sucessivas avaliações com vistas ao lançamento de novas cultivares ou à escolha de parentais para recombinação, é possível estimar os coeficientes de repetibilidade das variáveis estudadas e quantificar o número de determinações que devem ser realizadas em um caráter para obter-se uma avaliação fenotípica mais eficiente, em menor espaço de tempo e com menos custo. Portanto, o conhecimento da repetibilidade é importante para orientar programas de melhoramento genético, principalmente envolvendo espécies perenes.

O conceito de repetibilidade pode ser enunciado como sendo a correlação entre as medidas de determinado caráter em um mesmo indivíduo, cujas avaliações foram repetidas no tempo ou espaço. Expressa a proporção da variância total, que é explicada pelas variações proporcionadas pelo genótipo e pelas permanentes atribuídas ao ambiente comum (Cruz \& Regazzi, 1994) e, de acordo com Falconer (1981), representa o limite superior do coeficiente de herdabilidade. Valores altos da estimativa da repetibilidade do caráter indicam que é possível predizer o valor real do indivíduo com um número relativamente pequeno de medições (Cruz \& Regazzi, 1994); isto indica que pouco ganho em acurácia haverá com o aumento do número de medições repetidas. A repetibilidade tem sido utilizada com certa freqüência em diversas espécies perenes e semiperenes: seringueira (Gonçalves et al., 1982; Vasconcelos et al., 1985), cana-de-açúcar (Bressiani, 1993), Pínus (Cornacchia et al., 1995), cajueiro (Cavalcanti et al., 1999), alfafa (Pereira et al., 1998; Ferreira et al., 1999), aceroleira (Lopes et al., 2001), com a finalidade de elevar o índice de eficiência dos métodos de seleção.

O objetivo deste trabalho foi estimar os coeficientes de repetibilidade dos caracteres altura da planta, diâmetro da planta à altura do colo e peso líquido do palmito, e determinar o número mínimo de avaliações capaz de proporcionar níveis de certeza da predição do valor real dos indivíduos.

\section{MATERIALEMÉTODOS}

O experimento foi instalado em janeiro de 1998, no Campo Experimental do Matapi, pertencente ao Centro de Pesquisa Agroflorestal do Amapá - CPAF/AP. As 31 progênies consideradas provieram do Centro Nacional de Pesquisa da Amazônia Ocidental - CPAA, Manaus. As sementes foram obtidas a partir de polinização aberta de matrizes sem espinho, sendo, portanto, progênies de meios-irmãos. O teste de progênie foi plantado no Campo Experimental do Matapi, do CPAF/AP, da Embrapa. A área apresenta topografia plana, cobertura com vegetação de capoeira, clima tipo Ami, segundo a classificação de Köppen, com temperatura média anual de $27^{\circ} \mathrm{C}$, umidade relativa do ar média de $82 \%$ e precipitação média anual de $2.700 \mathrm{~mm}$. O solo é do tipo Latossolo Amarelo textura média.

As progênies foram avaliadas em experimento delineado em blocos casualizados, com três repetições, parcelas lineares de cinco plantas, espaçadas em 2,0 $\mathrm{m}$ x 1,0 $\mathrm{m}$ e bordadura composta por uma fileira em torno do experimento. As progênies foram avaliadas aos 15 meses $\left(1^{\mathrm{a}}\right.$ avaliação), 26 meses ( $2^{a}$ avaliação) e 37 meses ( $3^{a}$ avaliação) do plantio, coletando-se dados de altura da planta (medida do solo até o ponto de inserção da folha-guia e a primeira folha expandida), diâmetro da planta à altura do colo e peso líquido do palmito (palmito tipo exportação), conforme recomendações de Clement \& Bovi (2000). Não houve manejo de perfilhos, de tal modo que, na segunda e terceira avaliações, em 
muitos casos, foi avaliada mais de uma planta por touceira.

O coeficiente de repetibilidade (r) foi estimado por três procedimentos estatísticos, de tal forma que foi possível avaliar a consistência da estimativa obtida. Os métodos foram: análise de variância (ANOVA), componentes principais e análise estrutural. O número mínimo de medições necessárias para predizer o valor real dos indivíduos, com base em coeficiente de determinação genotípica $\left(\mathrm{R}^{2}\right)$ preestabelecido $(0,80,0,90 \mathrm{e}$ 0,95), foi estimado de acordo com a expressão fornecida por Cruz \& Regazzi (1994). Todas as análises estatísticas foram realizadas utilizando o programa computacional GENES (Cruz, 1997).

\section{RESULTADOS E DISCUSSÃO}

As estimativas dos coeficientes de repetibilidade obtidas pelos diferentes procedimentos estatísticos são apresentadas na Tabela 1. As estimativas foram divergentes entre os procedimentos empregados. Observa-se que as estimativas do coeficiente de repetibilidade obtidas pelo método da análise de variância (ANOVA) são sempre iguais ou inferiores às estimativas obtidas pelos métodos multivariados (análise estrutural e componentes principais) e que, pelo método dos componentes principais (baseado na matriz de co-variância) as estimativas foram sempre superiores às obtidas pelos demais métodos. Resultados semelhantes foram obtidos com Vasconcelos et al. (1985), Cornacchia et al. (1995) e Ferreira et. al (1999), que verificaram ser a repetibilidade melhor estimada por meio de métodos multivariados para as características produção de borracha em seringueira, volume em pínus e produção de matéria seca em alfafa, respectivamente.

TABELA 1 - Estimativas da repetibilidade dos caracteres altura da planta (AP), diâmetro da planta à altura do colo (DPC) e peso do palmito (PP). Centro de Pesquisa Agroflorestal do Amapá, Embrapa, Macapá, 2001.

\begin{tabular}{cccccc}
\hline & \multicolumn{3}{c}{ Componentes principais } & \multicolumn{2}{c}{ Análise-estrutural } \\
Caráter & Anova & Co-variância & Correlação & Co-variância & Correlação \\
\hline AP & 0,2301 & 0,5899 & 0,3104 & 0,2301 & 0,2416 \\
& $(47,28)$ & $(81,18)$ & $(57,45)$ & $(47,28)$ & $(48,88)$ \\
DPC & 0,2751 & 0,3990 & 0,2983 & 0,2751 & 0,2923 \\
& $(53,24)$ & $(67,69)$ & $(56,05)$ & $(53,24)$ & $(55,24)$ \\
PP & 0,2483 & 0,3876 & 0,2680 & 0,2401 & 0,2657 \\
& $(49,78)$ & $(66,54)$ & $(52,34)$ & $(48,67)$ & $(52,06)$ \\
\hline
\end{tabular}

${ }^{1}$ Valores referentes ao coeficiente de determinação associado ao coeficiente de repetibilidade.

As estimativas do coeficiente de repetibilidade, de maneira geral, são consideradas baixas, inferiores a 0,4 , revelando as dificuldades existentes para o melhorista em identificar os melhores valores genotípicos a partir da análise das médias fenotípicas obtidas, considerando apenas os três cortes efetuados. Em outras palavras, essas estimativas indicaram irregularidades na repetição do caráter entre uma avaliação e outra. Uma possível causa para as baixas estimativas obtidas pode ser a ausência de manejo da touceira, haja vista que ocorreu intensa competição entre as plantas dentro da touceira, o que afetou a expressão dos caracteres na segunda e terceira avaliações. Segundo Bovi (1994), para as condições de São Paulo, não há necessidade de promover-se o manejo dos perfilhos.

Na Tabela 2, encontram-se as estimativas do número de avaliações necessárias para ter-se diferentes valores de predição do valor real da população (ou coeficiente de determinação genotípico), obtidos a partir dos coeficientes de repetibilidade estimados pelo método dos componentes principais baseado na matriz de co-variância. Para o caráter altura da planta, três avaliações, na mesma touceira, são necessárias para ter-se predições com confiabilidade de $80 \%$. Para o mesmo percentual de confiabilidade, são necessárias seis avaliações para os caracteres diâmetro à altura do colo e peso líquido do palmito. Tal fato era esperado, haja vista que esses dois últimos caracteres são altamente correlacionados (Farias Neto, 1999)
TABELA 2 - Número de medições associado a vários coeficientes de determinação $\left(\mathrm{R}^{2}\right)$, estimado para os caracteres altura da planta (AP), diâmetro da planta à altura do colo (DPC) e peso de palmito líquido (PP). Centro de Pesquisa Agroflorestal do Amapá, Embrapa, Macapá, 2001.

\begin{tabular}{ccccc}
\hline Caracteres & Repetibilidade & $\mathrm{R}^{2}=0,80$ & $\mathrm{R}^{2}=0,90$ & $\mathrm{R}^{2}=0,95$ \\
\hline AP & 0,5899 & 2,78 & 6,25 & 13,21 \\
DPC & 0,3990 & 6,01 & 13,73 & 31,11 \\
PP & 0,3876 & 6,29 & 14,83 & 31,32 \\
\hline
\end{tabular}

\section{CONCLUSÕES}

1. As estimativas dos coeficientes de repetibilidade das características estudadas apresentaram baixa regularidade na superioridade das progênies de uma avaliação para outra. Para o caráter altura da planta, três avaliações são necessárias para ter-se predições com confiabilidade de $80 \%$. Para os caracteres diâmetro à altura do colo e peso de palmito, há a necessidade de seis avaliações, para que a seleção possa ser praticada com o mesmo percentual de confiabilidade.

2. Foram verificadas diferenças entre as estimativas dos coeficientes de repetibilidade obtidas pelo método da ANOVA e pelo método da análise estrutural (co-variância e correlação) com as obtidas pelo método dos componentes principais (co-variância).

\section{REFERÊNCIASBIBLIOGRÁFICAS}

BOVI, M.L.A. Palmito pupunha: informações básicas para o cultivo. Campinas. Instituto Agronômico, 1994. 10p. (Boletim Informativo).

BRESSIANI, J.A. Herdabilidade e repetibilidade na cultura da cana-deaçúcar. 1993. 66f. Dissertação (Mestrado em Genética e Melhoramento de Plantas)- Escola Superior de Agricultura "Luiz de Queiroz", Universidade de São Paulo, Piracicaba, 1993.

CAVALCANTI, J.J.V.; PAIVA, J.R. de; BARROS, L. de M.; CRISOSTOMO, J.R.; CORREA, M.P.F. Repetibilidade e número de avaliações necessárias à seleção de clones de cajueiro-anão-precoce. Fortaleza: Embrapa-CNPAT, 1999. 12p. ( Boletim de Pesquisa, 23).

CLEMENT, C.R.; BOVI, M.L.A. Padronização de medidas de crescimento e produção em experimentos com pupunheira para palmito. Acta Amazônica, Manaus, v.30, n.3, p. 349-368, 2000.

CORNACCHIA, G.C.; CRUZ, C.D.; PIRES, I.E. Estimativas do coeficiente de repetibilidade para características fenotípicas de procedências de Pinus tecunumanii (Schw.) Eguiluz \& Perry e Pinus caribae var. hondurensis Barret \& Golfari. Revista Árvore, Viçosa, v. 19, n.3, p. 333-345, 1995.

CRUZ, C.D. Programa Genes: aplicativo computacional em genética e estatística. Viçosa, MG: UFV, 1997.442p.

CRUZ, C.D.; REGAZZI, A.J. Modelos biométricos aplicados ao melhoramento genético. Viçosa: UFV, Imprensa Universitária, 1994. 390p.

FALCONER, D.S. Introdução à genética quantitativa. Viçosa:UFV, 1981. $279 p$.

FARIAS NETO, J.T. Estimativas de parâmetros genéticos em progênies de meios-irmãos de pupunheira. Boletim de Pesquisa Florestal, Colombo, PR, v.39, p.109-17, 1999.

FERREIRA, R.P.; BOTREL, M.A.; PEREIRA, A.V.; CRUZ, C.D. Avaliação de cultivares de alfafa e estimativas de repetibilidade de caracteres forrageiros. Pesquisa Agropecuária Brasileira, Brasília, v. 34, n. 6, p.995-1002, 1999.

GONÇALVES, P.S. de; ROSSETTI, A.G.; PAIVA, J.R. de. Coeficiente de repetibilidade e eficiência do miniteste de produção na seleção de plantas de seringueira. Pesquisa Agropecuária Brasileira, Brasília, v. 17, n. 2, p.233-237, 1982.

LOPES, R.; BRUCKNER, C.H.; CRUZ, C.D.; LOPES, M.T.G.; FREITAS, G.B. de. Repetibilidade de características do fruto de aceroleira. Pesquisa Agropecuária Brasileira, Brasília, v.36, n.3, p.507-513, 2001. 
PAIVA, J.R. de; RESENDE, M.D.V. de; CORDEIRO, E.R. Avaliação do número de colheitas na produção de progênies de aceroleira, repetibilidade e herdabilidade de caracteres. Revista Brasileira de Fruticultura, Jaboticabal, v.23, n.1, p.102-107, 2001.

PEREIRA, A.V.; FERREIRA, R.P.; CRUZ, C.D.; FREITAS, V.P.; OLIVEIRA, T.A. Comportamento de alfafa cv. Crioula de diferentes origens e estimativas dos coeficientes de repetibilidade para caracteres forrageiros. Revista Brasileira de Zootecnia, Viçosa, v.27, n.4, p.686690, 1998
VASCONCELOS, M.E.C.; GONÇALVES,P.S.;PAIVA,J.R.; VALOIS, A.C.C. Métodos de estimação do coeficiente de repetibilidade no melhoramento da seringueira. Pesquisa Agropecuária Brasileira, Brasília, v.20, n.4, p.433-437, 1985.

TONEF, R.M.; FERREIRA, L.G.S.; OTOBONI, J.L.M. A cultura da pupunha. Campinas:CATI, 1999. 44p. (Boletim Informativo). 